\title{
Spectroscopic Characterization and Investigation of the Dynamic of Charge Compensation Process of Supramolecular Films Derived from Tetra-2-pyridyl-1,4-pyrazine Ligand
}

\author{
Wendel A. Alves, ${ }^{*, a}$ Valeria Pfaffen, ${ }^{b}$ Patrícia I. Ortiz, ${ }^{b}$ Susana I. Córdoba de Torresi ${ }^{c}$ and \\ Roberto M. Torresi ${ }^{c}$
}

${ }^{a}$ Centro de Ciência Naturais e Humanas, Universidade Federal do ABC, 09210-170 Santo André-SP, Brazil

${ }^{b}$ Instituto de Investigaciones en Físico-Química de Córdoba (INFIQC), Departamento de Físico-Química, Faculdad de Ciencias Químicas, Universidad Nacional de Córdoba, Ciudad Universitária, 5000 Córdoba, Argentina

'Instituto de Química, Universidade de São Paulo, CP 26077, 05513-970 São Paulo-SP, Brazil

\begin{abstract}
Este trabalho descreve a caracterização espectroscópica por infravermelho e o estudo da dinâmica de compensação de cargas do filme supramolecular FeTPPZFeCN derivado do ligante tetra-2-piridil-1,4-pirazina (TPPZ) com hexacianoferrato, bem como o filme híbrido envolvendo FeTPPZFeCN e uma matriz de polipirrol (PPy). Para o filme supramolecular, foi observado um aumento no fluxo de ânion em solução contendo $\mathrm{K}^{+}$em relação ao $\mathrm{Li}^{+}$, que parece estar relacionado ao tamanho do raio iônico cristalino do $\mathrm{K}^{+}$. O processo de eletroneutralização é discutido em termos de interação eletrostática entre cátions e centros metálicos na matriz hospedeira. A natureza do processo de compensação de carga difere de outros eletrodos modificados derivados do azul da Prússia, onde somente cátions tais como $\mathrm{K}^{+}$participam no processo de eletroneutralização. No caso do filme híbrido FeTPPZFeCN/PPy, a magnitude do fluxo de ânions é também dependente da identidade do ânion em diferentes eletrólitos de suporte.
\end{abstract}

This work describes the infrared spectroscopy characterization and the charge compensation dynamics in supramolecular film FeTPPZFeCN derived from tetra-2-pyridyl-1,4-pyrazine (TPPZ) with hexacyanoferrate, as well as the hybrid film formed by FeTPPZFeCN and polypyrrole (PPy). For supramolecular film, it was found that anion flux is greater in a $\mathrm{K}^{+}$containing solution than in $\mathrm{Li}^{+}$solution, which seems to be due to the larger crystalline ionic radius of $\mathrm{K}^{+}$. The electroneutralization process is discussed in terms of electrostatic interactions between cations and metallic centers in the hosting matrix. The nature of the charge compensation process differs from others modified electrodes based on Prussian blue films, where only cations such as $\mathrm{K}^{+}$participate in the electroneutralization process. In the case of FeTPPZFeCN/PPy hybrid film, the magnitude of the anions's flux is also dependent on the identity of the anion of the supporting electrolyte.

Keywords: tetra-2-pyridyl-1,4-pyrazine (TPPZ), hexacyanoferrate, polypyrrole, electrochemical quartz crystal microbalance (EQCM)

\section{Introduction}

In recent years, the synthesis of oligo- and polymer transition metal complexes capable of electronic communication between redox active sites has been extensively studied. ${ }^{1}$ Complexes which incorporate polypyridine-type ligands are particularly attractive because they form very stable complexes with a wide range of transition metals and also stabilize complexes in multiple oxidation states. ${ }^{2}$ Their redox properties have been

*e-mail: wendel.alves@ufabc.edu.br extensively studied and have been found to act as excellent bridges that enhance electronic communication between metal centers. ${ }^{3}$

It is known that a bridging ligand like tetra-2-pyridyl1,4-pyrazine (TPPZ) exhibits a remarkable coordination versatility, even effectively bridging bimetallic and trimetallic complexes. ${ }^{4}$ Moreover, TPPZ was shown to be an ideal candidate for a variety of applications. Recent patents make use of this organic ligand and its complexes: in the construction of methanol-based fuel cells, ${ }^{5}$ for sequestering iron for disease prevention, ${ }^{6}$ in molecular sensors, ${ }^{7}$ and in photodynamic therapy. ${ }^{8}$ Structural studies also continue, 
with a particular emphasis on the synthesis of chiral derivatives of the electronically highly conjugated tetra-2pyridyl-1,4-pyrazine bridging ligand, ${ }^{9}$ for development of electronic and optical materials that exploit the extraordinary ability of TPPZ to mediate intermetallic interactions. ${ }^{10}$ TPPZ, along with other related 2,2':6',2"'-terpyridine derivatives, has been effectively employed as a bridging ligand for incorporation into supramolecular systems, facilitating the formation of multinuclear systems designed to study directionally and spatially controlled electronand/or energy-transfer processes. ${ }^{11}$

It was previously shown, ${ }^{12}$ a chemically modified electrode prepared by the eletropolymerization of iron complexes derived from TPPZ with hexacyanoferrate species forming a very stable supramolecular complex, probably similar to the Prussian blue (PB) structure, as shown in Figure 1. The inorganic polymer formed shows a special structure that combines a mixed valence system with an organic ligand with strong $\pi$-character and a high electronic conduction. However, this modified electrode showed some limitations such as low stability after some amperometric studies in both phosphate buffer and $\mathrm{NaCl}$ solutions, monitored by electrochemical impedance spectroscopy technique (EIS). To solve this problem a polypyrrole (PPy) matrix was used for the immobilization of the catalytically active compound onto electrode surfaces. The hybrid material shows excellent catalytic activity towards $\mathrm{H}_{2} \mathrm{O}_{2}$ detection in the presence of either $\mathrm{K}^{+}$ or $\mathrm{Na}^{+}$ions and can be used as redox mediator in a glucose biosensor. However, this study did not yield significant information on the spectroscopic characterization of the precursor compound derived from iron complex containing TPPZ structure and the characterization of the dynamic of the charge compensation processes in the inorganic polymer obtained by electropolymerization of iron complexes derived from TPPZ ligand with hexacyanoferrate species, FeTPPZFeCN films. ${ }^{12}$

In this contribution, it is reported the characterization of FeTPPZFeCN and FeTPPZFeCN/PPy hybrid films, by FTIR spectroscopy and the dynamic of the charge compensation processes was studied by using simultaneous electrochemical quartz crystal microbalance (EQCM) and cyclic voltammetry (CV) experiments. To analyze the effect of anions or cations, four different electrolytic solutions: $\mathrm{NaCl}, \mathrm{KCl}, \mathrm{LiCl}$ or $\mathrm{KClO}_{4}$ were used. The electroneutralization process was discussed in connection with the ionic radius, and electrostatic interactions between cations and metallic centers in the hosting matrix. The results are compared to others modified electrodes derived from PB films.

\section{Experimental}

All reagents were of analytical grade, purchased from different sources, and used without further purification. Elemental analyses were performed by using a PerkinElmer $2400 \mathrm{CHN}$ Elemental Analyzer. Infrared spectra of solid samples diluted in $\mathrm{KBr}$ were recorded on a Bomem spectrometer, model MB-102, in the range $4000-400 \mathrm{~cm}^{-1}$. Spectra of the supramolecular complex, PPy and hybrid material were obtained after removing the electrode in the oxidized state.

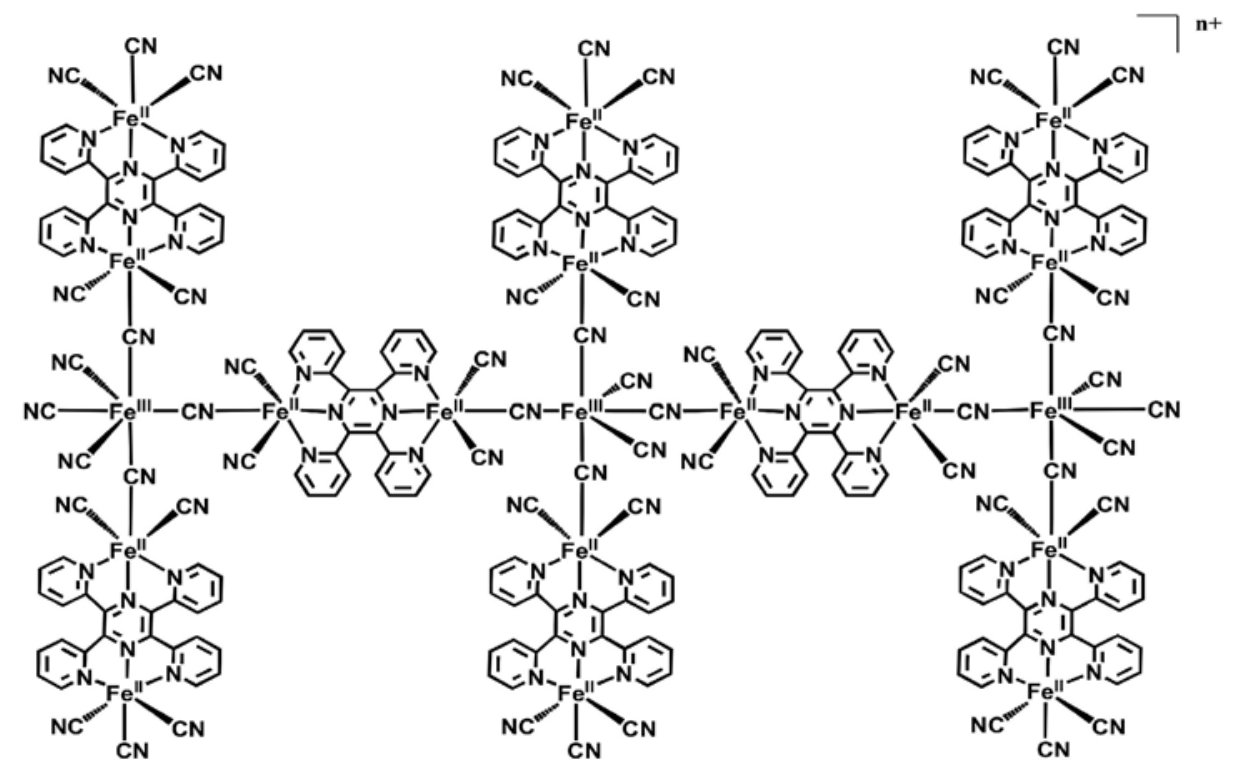

Figure 1. Schematic structure of the FeTPPZFeCN complex studied. 
For electrochemical experiments, the counter electrode was a platinum electrode $\left(10 \mathrm{~cm}^{2}\right.$ geometrical area) and a saturated $\mathrm{Ag} / \mathrm{AgCl} / \mathrm{Cl}^{-}$was the reference electrode. Working electrodes were $6 \mathrm{MHz}$ AT-cut quartz crystals coated with gold by thermal vacuum deposition, followed by electrodeposition of $\mathrm{Pt}$ from a $10 \mathrm{mmol} \mathrm{L}^{-1} \mathrm{H}_{2} \mathrm{PtCl}_{6}+$ $1 \mathrm{~mol} \mathrm{~L}^{-1} \mathrm{HCl}$ solution. Typically, in the case of the hybrid materials $80 \mathrm{mg} \mathrm{cm}^{-2}$ was deposited; assuming a film density of $1.5 \mathrm{~g} \mathrm{~cm}^{-3},{ }^{13}$ a film thickness of $500 \mathrm{~nm}$ can be estimated. The mass deposited in the case of the complex is 10 times smaller; so that, it can be inferred that the film is even thinner. Considering that in both cases the film thickness were smaller compared with the thickness of the crystal and it behaves in a rigid manner. Thus, the Sauerbrey treatment $(\Delta f=-K \Delta m)$ can be used to relate the mass changes per unit area, $\Delta m$ (in $\mathrm{g} \mathrm{cm}^{-2}$ ), to the resonance frequency shift $\Delta f($ in $\mathrm{Hz}) .{ }^{14}$ The integral sensitivity constant $\left(K=6.45 \times 10^{7} \mathrm{~cm}^{2} \mathrm{~Hz} \mathrm{~g}^{-1}\right)$ was obtained by calibration using silver deposition. ${ }^{15}$ All electrogravimetric analysis was carried out after that the voltammogram was invariant with time. This condition was achieved after 5 electrochemical scans. Electrochemical measurements were carried out using a Omnimetra PG-3901 potentiostat/galvanostat connected to a PC-microcomputer for acquiring and storing data. The experimental details for EQCM measurements have been described previously. ${ }^{16}$

Preparation of $\left[\mathrm{Fe}_{2}(\mathrm{TPPZ})\left(\mathrm{SO}_{4}\right)_{3}\right]$ complex and electrochemical synthesis of FeTPPZFeCN and FeTPPZFeCN/PPy hybrid films onto a Pt electrode were carried out according to previously published procedures. ${ }^{12}$ After deposition, films were rinsed with purified water and placed in the electrochemical cell with $0.1 \mathrm{~mol} \mathrm{~L}^{-1}$ monomer-free aqueous solutions of $\mathrm{KCl}, \mathrm{KClO}_{4}, \mathrm{NaCl}$ and $\mathrm{LiCl}$ as electrolyte.

\section{Results and Discussion}

\section{Preparation and characterization}

The synthesis and characterization by elemental analysis and Raman spectroscopy of a symmetrical dinuclear iron $\left[\mathrm{Fe}_{2}(\mathrm{TPPZ})\left(\mathrm{SO}_{4}\right)_{3}\right]$ complex derived from TPPZ ligand has been previously reported. ${ }^{12}$ The electropolymerization of the $\left[\mathrm{Fe}_{2}(\mathrm{TPPZ})\left(\mathrm{SO}_{4}\right)_{3}\right]$ complex with hexacyanoferrate species onto a Pt electrode was carried out using the same conditions described in literature. ${ }^{12}$ The formation mechanism of this stable structure FeTPPZFeCN onto the electrode surface by sequential covalent processes takes place during the negative sweep in a similar way that the formation of PB. ${ }^{17}$ The film growth occurs during negative potential scans because, at sufficiently low potentials $(<0.3 \mathrm{~V})$,
hexacyanoferrate(III) is reduced to hexacyanoferrate(II) that forms a deposited film on the electrode surface with iron(III) complex containing TPPZ structure. The mechanistic aspects of electrodeposition of FeTPPZFeCN film via voltammetric potential cycling was also reported previously. ${ }^{12}$

The supramolecular film FeTPPZFeCN was scraped from the electrode surface and the solid powder was characterized by FTIR analysis. The same methodology was used to obtain the hybrid film of FeTPPZFeCN/PPy. Figure 2 shows the FTIR spectra of the $\left[\mathrm{Fe}_{2}(\mathrm{TPPZ})\left(\mathrm{SO}_{4}\right)_{3}\right]$ complex (curve a), FeTPPZFeCN supramolecular synthetized compound (curve $b$ ), PPy (curve $c$ ), and the

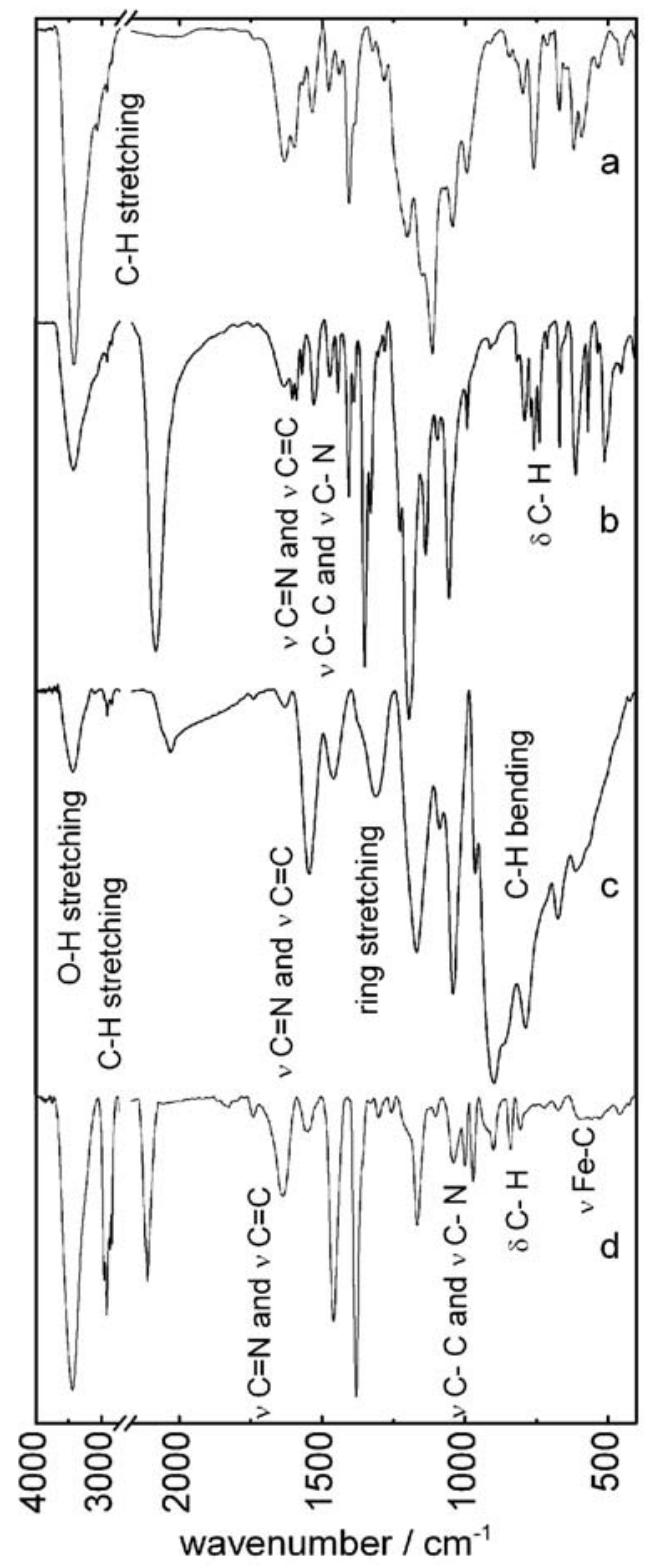

Figure 2. FTIR spectra of $\left[\mathrm{Fe}_{2}(\mathrm{TPPZ})\left(\mathrm{SO}_{4}\right)_{3}\right]$ (curve $a$ ), supramolecular synthetized compound FeTPPZFeCN (curve $b$ ), PPy (curve $c$ ), and the hybrid material FeTPPZFeCN/PPy (curve $d$ ). 
FeTPPZFeCN/PPy hybrid material (curve $d$ ). As it can be seen, the strong and broad absorption band centered at $3440 \mathrm{~cm}^{-1}$ for all isolated compounds is related to the $\mathrm{O}-\mathrm{H}$ stretching of water molecules with hydrogen bonds. The presence of TPPZ in $\left[\mathrm{Fe}_{2}(\mathrm{TPPZ})\left(\mathrm{SO}_{4}\right)_{3}\right], \mathrm{FeTPPZFeCN}$ and FeTPPZFeCN/PPy in curves $a, b$ and $d$ respectively, is revealed by the bands located at $3100-2900 \mathrm{~cm}^{-1}$ corresponding to the aromatic $\mathrm{C}-\mathrm{H}$ stretching vibrations, those at $1650-1550 \mathrm{~cm}^{-1}$ to $v(\mathrm{C}=\mathrm{N})$ and $v(\mathrm{C}=\mathrm{C})$ stretchings (in the case of the hybrid material this region is a little obscured by absorptions of the PPy matrix), those at $1470-1020 \mathrm{~cm}^{-1}$ corresponding to $v(\mathrm{C}-\mathrm{C})+v(\mathrm{C}-\mathrm{N})$ modes and those at $810-710 \mathrm{~cm}^{-1}$ assigned to aromatic $\mathrm{C}-\mathrm{H}$ deformation vibrations. ${ }^{18}$ Most of them are shifted to lower frequencies when compared to those of uncoordinated TPPZ suggesting the coordination of TPPZ ligand to metallic centers.

Curve $c$ shows the spectrum of PPy doped with chloride anions. The bands at 1548, 1310, and $1180 \mathrm{~cm}^{-1}$ correspond to ring stretching. The band at $1042 \mathrm{~cm}^{-1}$ is assigned to $\mathrm{C}-\mathrm{H}$ and $\mathrm{N}-\mathrm{H}$ bending and bands at 914, 784, and $670 \mathrm{~cm}^{-1}$ are related to $\mathrm{C}-\mathrm{H}$ bending. The spectrum is fully in agreement with literature data. ${ }^{18}$ Curve $d$ shows the spectrum for the hybrid material FeTPPZFeCN/PPy, where it can be seen that there is an overlap between the bands of the PPy (curve $d$ ) and FeTPPZFeCN (curve $b$ ) assigned to polypyridine ligands as already described. Moreover, the presence of bands assigned to $-\mathrm{C} \equiv \mathrm{N}$ group at ca. $2100 \mathrm{~cm}^{-1}$ and also the bands at $560-570 \mathrm{~cm}^{-1}$ assigned to $\mathrm{Fe}-\mathrm{C}$ stretching modes, which are also presented in compound FeTPPZFeCN, indicate the formation of the hybrid material being immobilized in the polymer matrix forming a homogeneous coating. ${ }^{12}$

\section{EQCM studies}

The study of the ion and solvent transport behavior during the redox reaction for both modified electrodes, FeTPPZFeCN and FeTPPZFeCN/PPy, was performed by using the EQCM technique. The experimental results were recorded when cyclic voltammograms were invariant with time.

In summary to analyze the EQCM results in a quantitative form, it is possible to write the global mass change caused by participation of cations, anions and solvent molecules. ${ }^{19}$ Thus, the global mass change during a given voltammetric scan $\left(\Delta m_{(E)}\right)$ can be written as:

$\Delta \mathrm{m}_{(\mathrm{E})}=\mathrm{W}_{\mathrm{C}^{+}} \xi_{\mathrm{C}^{+}(\mathrm{E})}+\mathrm{W}_{\mathrm{A}^{-}} \xi_{\mathrm{A}^{-}(\mathrm{E})}+\mathrm{W}_{\mathrm{S}} \xi_{\mathrm{S}(\mathrm{E})}$

where $\mathrm{W}$ is the molar mass of cations $\left(\mathrm{C}^{+}\right)$, anions $\left(\mathrm{A}^{-}\right)$or solvent molecules $(\mathrm{S})$ and $\xi$ is the amount of cations, anions or solvent molecules undergoing transport. Considering electroneutralization conditions within the bulk of the film, the charge involved in the redox process can be related to the number of moles of ionic species in the following way

$q(E)=-F \xi_{C^{+}(E)}+F \xi_{A^{-}(E)}$

where $\mathrm{F}$ is the Faraday constant and the charge of cations and anions are 1 and -1 respectively. By combining equations 1 and 2, one obtains the amount of cations and anions, each one with a contribution from solvent, as a function of the charge density and mass,

$\xi_{C^{+}(E)}+\frac{W_{S}}{W_{C A}} \xi_{S(E)}=\frac{\Delta m_{(E)}}{W_{C A}}-\frac{W_{A^{-}}}{W_{C A}} \frac{q(E)}{F}$

for cations + solvent, and

$\xi_{A^{-}(E)}+\frac{W_{S}}{W_{C A}} \xi_{S(E)}=\frac{\Delta m_{(E)}}{W_{C A}}+\frac{W_{C^{+}}}{W_{C A}} \frac{q(E)}{F}$

for anions + solvent; $\mathrm{W}_{\mathrm{CA}}$ being the salt molar mass.

By differentiation of equations 3 and 4 one obtains the fluxes of cations and anions with a contribution of solvent as a function of the current density and mass flux

$\frac{d\left(\xi_{C^{+}(E)}+\frac{W_{S}}{W_{C A}} \xi_{S(E)}\right)}{d t}=\frac{1}{W_{C A}} \frac{d\left(\Delta m_{(E)}\right)}{d t}-\frac{W_{A^{-}}}{W_{C A}} \frac{j_{(E)}}{F}$

and

$\frac{d\left(\xi_{A^{-}(E)}+\frac{W_{S}}{W_{C A}} \xi_{S(E)}\right)}{d t}=\frac{1}{W_{C A}} \frac{d\left(\Delta m_{(E)}\right)}{d t}+\frac{W_{C^{+}}}{W_{C A}} \frac{j_{(E)}}{F}$

The flux is considered positive when species are inserted in the polymer film and negative in the case of ejected species. Figure 3 shows the $j / E$ and $\Delta m / E$ potentiodynamic profiles of FeTPPZFeCN film in $0.1 \mathrm{~mol} \mathrm{~L}^{-1} \mathrm{KCl}, \mathrm{NaCl}$ and $\mathrm{LiCl}$ electrolytic solution at $50 \mathrm{mV} \mathrm{s}^{-1}$. It can be seen that in $\mathrm{NaCl}$ and $\mathrm{LiCl}$ electrolytic solutions the cyclic voltammogram for complex film does not exhibit well-defined peaks assigned to $\mathrm{Fe}^{\mathrm{III}} / \mathrm{Fe}^{\mathrm{II}}$ redox process as observed in $\mathrm{KCl}$ solution; moreover, the current density observed in $\mathrm{Na}^{+}$and $\mathrm{Li}^{+}$is smaller than in $\mathrm{K}^{+}$electrolytes, suggesting that the redox activity of the supramolecular film is controlled by the size of the cation. By considering the mass changes it can be observed that while in both, $\mathrm{KCl}$ and $\mathrm{NaCl}$ solutions oxidation is followed by a global increase of mass, in $\mathrm{LiCl}$ occurs a decrease of mass when the film is oxidized. Evidently, the ionic compensation 
dynamics depends on the chemical nature of the cation of the electrolyte, specifically of mass/charge relationship. In order to analyze the ionic and solvent fluxes in a quantitative way, plots of both fluxes were build-up by using equations 5 and 6 for this supramolecular film in different electrolytic solutions and it is shown in Figure 4. It can be seen that molar fluxes depend on the chemical nature of the cation, as shown in Figure 3. In the case of $\mathrm{KCl}$ electrolyte, the charge compensation process is achieved mainly by the movement of the choride ions and the $\mathrm{K}^{+}$participation is almost negligible. This is clearly from the figure because the flux profile is the mirror image of the voltammogram shown in Figure 3a. In the case of $\mathrm{Na}^{+}$, the participation of both cations and anions take place at more positive potentials. The situation is completely opposite in the case of $\mathrm{LiCl}$ where the cations are the main responsibles for the charge compensation. Thus, it seems that the cation participation is related to electrostatic interaction of the cations and the electric charge in the complex film. The differences observed between them can be explained in terms of their charge/size $\left(Z / r_{\mathrm{k}}{ }^{2}\right)$ relationship, where $\mathrm{Z}$ is the charge number of the atomic core and $r_{\mathrm{k}}$ is the crystalline ionic radius. ${ }^{20}$ In this specific case, $Z / r_{\mathrm{k}}{ }^{2}$ of $1.235,0.743$ and 0.433 for $\mathrm{Li}^{+}, \mathrm{Na}^{+}$and $\mathrm{K}^{+}$, respectively, were calculated ${ }^{20}$ indicating that a more positive matrix

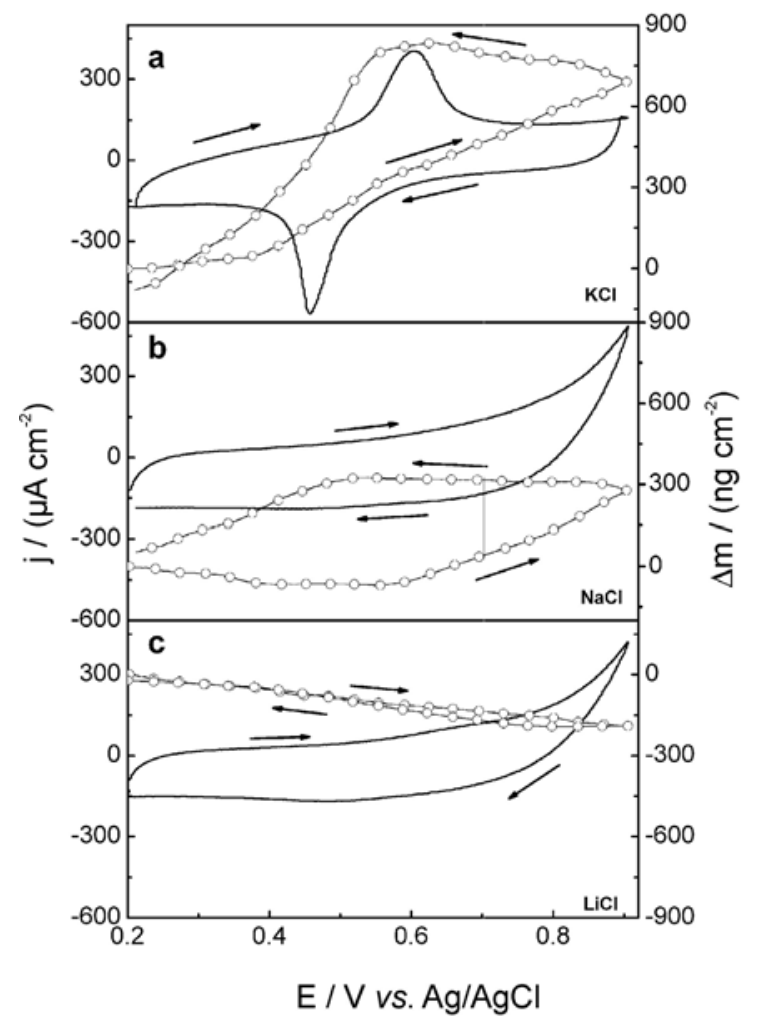

Figure 3. Potentiodynamic $j / E$ (full line) and $\Delta m / E$ (open circles) profiles for FeTPPZFeCN films in $0.1 \mathrm{~mol} \mathrm{~L}^{-1} \mathrm{KCl}$ (a), $\mathrm{NaCl}$ (b) and $\mathrm{LiCl}$ (c) electrolytic solutions. Film thickness $<<500 \mathrm{~nm}$. $v=50 \mathrm{mV} \mathrm{s}^{-1}$. produced upon oxidation will easily allow the movement of cations with higher charge/size relationship, but, this does not imply in higher electroactivity. It is clear that the highest electroactivity of FeTPPZFeCN films is related to the movement of anions.

Regarding to solvent flux, it is possible to consider two different situations: $(i)$ water molecules move together with cations (as a solvation shell) or (ii) water molecules are up taken by the film during a swelling process produced by the change in volume due to the redox reaction. It is not possible to separate solvent from ion contribution; so, the role played by solvent cannot be defined.

The performance in the presence of $\mathrm{K}^{+}$ions is completely different when compared to other modified electrodes based on PB films. ${ }^{21}$ Particularly, as it is well-known, that during the redox reactions of $\mathrm{PB}$ the charge balance is carried out by the insertion/ejection of $\mathrm{K}^{+}$; also $\mathrm{Rb}^{+}, \mathrm{Cs}^{+}$and $\mathrm{NH}_{4}^{+}$ were found to allow the cyclic electrochemical reactivity of $\mathrm{PB} .^{22}$ This behavior has been explained in terms of the hydrated ionic radii and the channel radius of the $\mathrm{PB}$ lattice $(\sim 1.6 \AA)$, which will easy accommodate $\mathrm{K}^{+}, \mathrm{Rb}^{+}, \mathrm{Cs}^{+}$and $\mathrm{NH}_{4}^{+}$with hydrated radii of $1.25,1.28,1.19$ and $1.25 \AA$, respectively. ${ }^{23}$ This is not the case for $\mathrm{Na}^{+}$with a hydrated radius of $2.76 \AA$, and this is the reason for the total loss of electroactivity of $\mathrm{PB}$ films in $\mathrm{Na}^{+}$containing electrolytes. Therefore, the contradiction between our results and those reported to others modified electrodes derived from PB films may be related to the change in structure of the film due to the coordination to the TPPZ ligand.

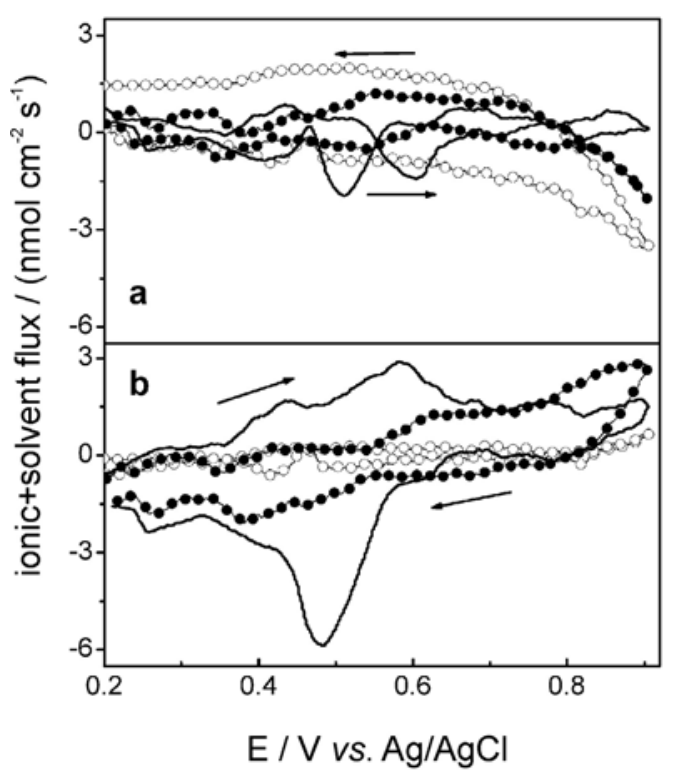

Figure 4. Cation (a) and anion (b) flux as a function of potential for FeTPPZFeCN films in $0.1 \mathrm{~mol} \mathrm{~L}^{-1} \mathrm{KCl}$ (full line), $\mathrm{NaCl}$ (full circle) and $\mathrm{LiCl}$ (open circle) electrolytic solutions. $v=50 \mathrm{mV} \mathrm{s}^{-1}$. Data calculated from Figure 3. 
In order to study the influence of the anion structure on the charge compensation processes, EQCM experiments were performed in $\mathrm{KClO}_{4}$ solutions. Figure 5 shows the cyclic voltammogram obtained in $0.1 \mathrm{~mol} \cdot \mathrm{L}^{-1} \mathrm{KClO}_{4}$ electrolyte is very similar to those obtained for $\mathrm{KCl}$ solutions showing current peaks at $0.45 \mathrm{~V}$ and $0.58 \mathrm{~V}$ assigned to $\mathrm{Fe}^{\mathrm{III}} / \mathrm{Fe}^{\mathrm{II}}$ redox process and a global increase of mass during oxidation followed by the corresponding decrease of mass during reduction. It is observed that after the oxidation of the metallic center the mass continuous increase, even during the reverse scan. This fact together with the big hysteresis observed could be explained considering the high sweep rate used and the low kinetics of the ionic exchange. Significant differences between the molar fluxes during the cyclic voltammograms for the $\mathrm{KCl}$ (Figure 4) and $\mathrm{KClO}_{4}$ (Figure 5) electrolytic solutions can be inferred. As already discussed before, in $\mathrm{KCl}$ solution the microbalance data indicate that the participation of $\mathrm{K}^{+}$in the charge compensation process was almost negligible and most of the charge was compensated by the insertion of chloride ions. The behavior observed in $\mathrm{KClO}_{4}$ solution is completely different and the molar fluxes of cations + solvent and anions + solvent are equivalent, as demonstrated by the fact that both fluxes $v s$. potential profiles follows the $\mathrm{j} / \mathrm{E}$ curves. This is an indication that both species are playing equivalent roles in the charge compensation process. However, the magnitude of the anions's flux is dependent on the identity of the anion of the supporting electrolyte. ${ }^{24}$ In fact, it has been noted that for FeTPPZFeCN film in $0.1 \mathrm{~mol} \mathrm{~L}^{-1}$ $\mathrm{KClO}_{4}$ electrolyte solution, the anion participation is smaller than in $\mathrm{KCl}$ solutions. This phenomenon could be interpreted considering that a portion of perchlorate ions is much less "leaky" towards supporting electrolyte penetration than the $\mathrm{Cl}^{-}$in the modified electrode, thereby for each electron injected/ejected to/from supramolecular film, $\mathrm{K}^{+}$ions are also intercalated/deintercalated to compensate the charge, as shown in Figure 5.

From the results obtained in different electrolytic solutions, it is possible to conclude that charge compensation dynamics is controlled not only by the chemical nature of ions, but also by the configuration of the matrix; that is to say, the space available for ion incorporation and overall internal charge present in the mixed-valence complex.

The complex film described in this work showed some limitations such as low stability after some voltammetric studies in different electrolytic solutions. ${ }^{12}$ In order to overcome this problem a PPy film was used for the immobilization of catalytically active compound FeTPPZFeCN onto electrode surfaces. The electrodeposition of the complex and PPy matrix onto a platinum electrode was carried out by applying triangular

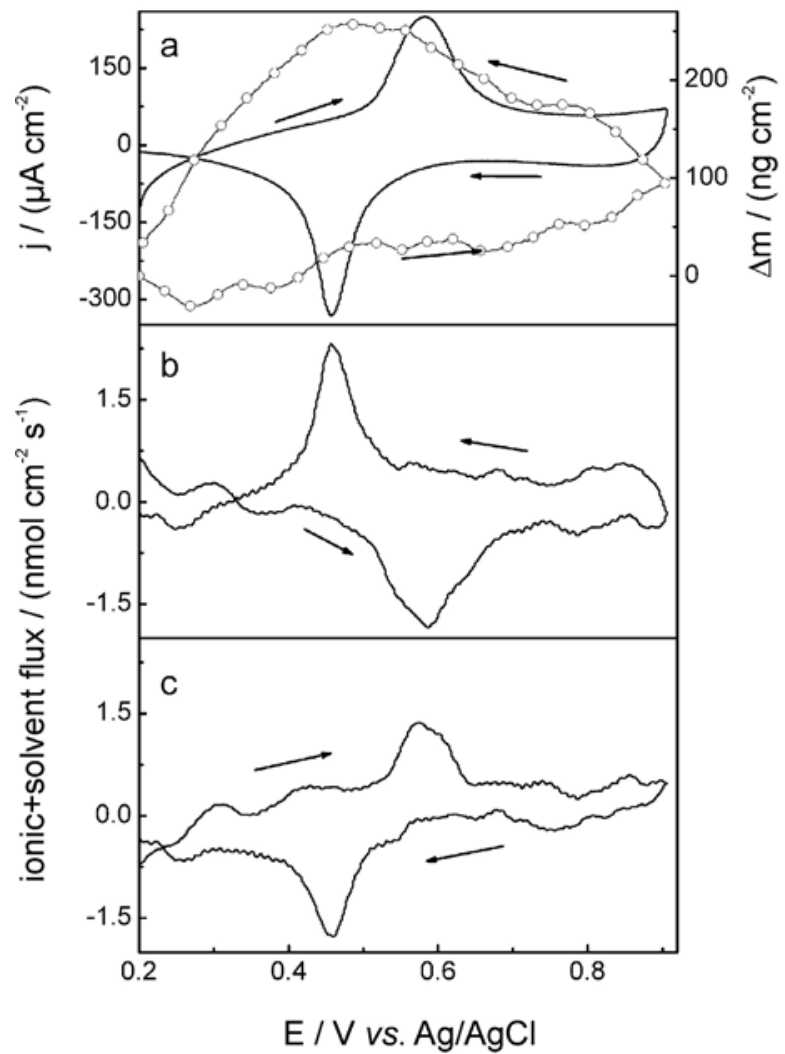

Figure 5. (a) Potentiodynamic $j / E$ (full line) and $\Delta m / E$ (open circle) profiles for FeTPPZFeCN films; (b) cation and (c) anion molar fluxes as a function of potential. Data calculated from Figure 5a. Electrolytic solution: $0.1 \mathrm{~mol} \mathrm{~L}^{-1} \mathrm{KClO}_{4}$. Film thickness $<<500 \mathrm{~nm}$. $v=50 \mathrm{mV} \mathrm{s}^{-1}$.

potential sweeps in the -0.3 to $0.9 \mathrm{~V}$ potential range. As it is well known, the polymerization of pyrrole occurs during the oxidation sweeps at positive potentials; while the deposition of complex FeTPPZ occurs during the negative part of the potential scan. So that, the simultaneous deposition of both PPy and supramolecular complex forms a homogeneous coating. ${ }^{12}$ Figure 6 shows the $\mathrm{j} / \mathrm{E}$ and $\Delta \mathrm{m} / \mathrm{E}$ profiles obtained with a FeTPPZFeCN/PPy film in different electrolytes. In this case, it is observed that the shape of the voltammograms and mass changes are approximately the same independently on the electrolytes. It can be seen that in all cases the oxidation process is accompanied by a mass increase and decrease of mass during the reduction process.

Figure 7 shows the molar fluxes for a hybrid film FeTPPZFeCN/PPy as a function of potential for $\mathrm{KCl}, \mathrm{NaCl}$ and $\mathrm{LiCl}$ electrolytes. During the anodic sweep, the flux of ejected cations + solvent is maximum at more positive potentials especially in $\mathrm{Li}^{+}$containing electrolytes, probably due to higher charge/size relationship as was discussed before. ${ }^{25}$ It can be expected that smaller cations like $\mathrm{Li}^{+}$ and $\mathrm{Na}^{+}$(considering that these cations do not move with all hydration sphere) can move faster than $\mathrm{K}^{+}$through the 
polymer matrix in order to compensate the charge created during the cycling. The molar flux of anions + solvent shows the same contribution during the charge compensation process as shown in Figure 7. The extent of the anion

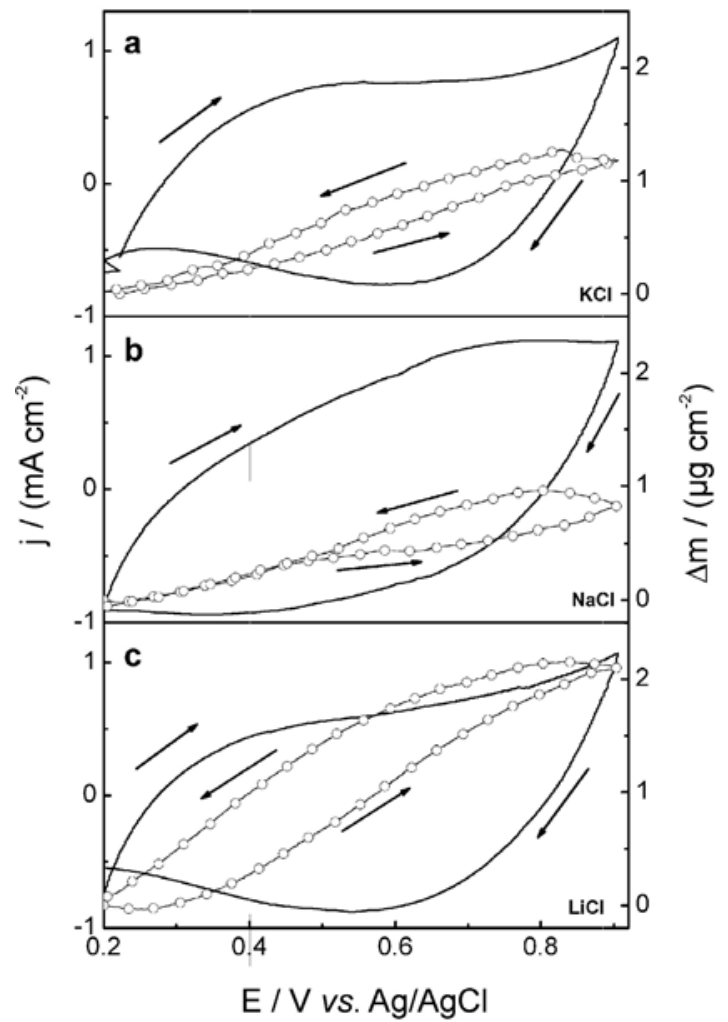

Figure 6. Potentiodynamic $j / E$ (full line) and $\Delta m / E$ (open circle) profiles for $\mathrm{FeTPPZFeCN} / \mathrm{PPy}$ films in $0.1 \mathrm{~mol} \mathrm{~L}^{-1} \mathrm{KCl}$ (a), $\mathrm{NaCl}$ (b) and $\mathrm{LiCl}$ (c) electrolytic solutions. Film thickness $=500 \mathrm{~nm} . v=50 \mathrm{mV} \mathrm{s}^{-1}$.

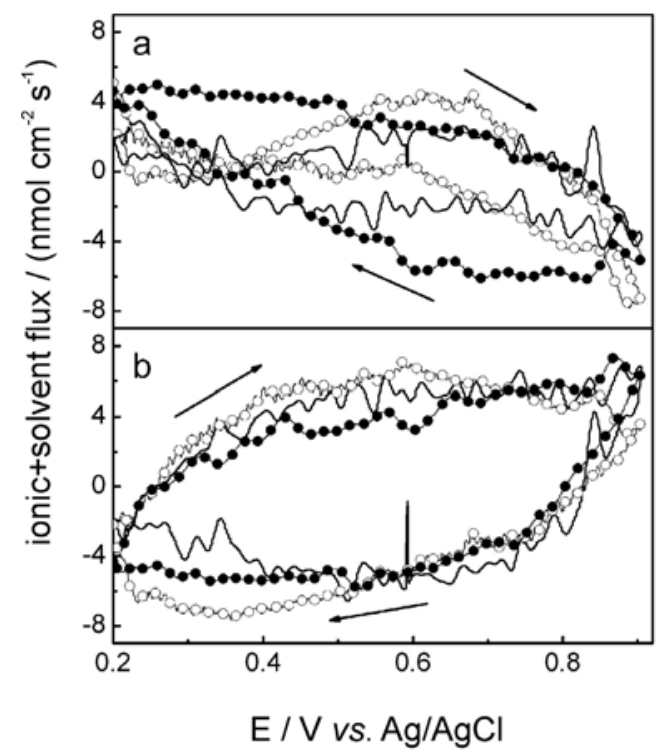

Figure 7. Cation (a) and anion (b) flux as a function of potential for FeTPPZFeCN/PPy films $0.1 \mathrm{~mol} \mathrm{~L}^{-1} \mathrm{KCl}$ (full line), $\mathrm{NaCl}$ (full circle) and $\mathrm{LiCl}$ (open circle) electrolytic solutions. $v=50 \mathrm{mV} \mathrm{s}^{-1}$. Data calculated from Figure 6.

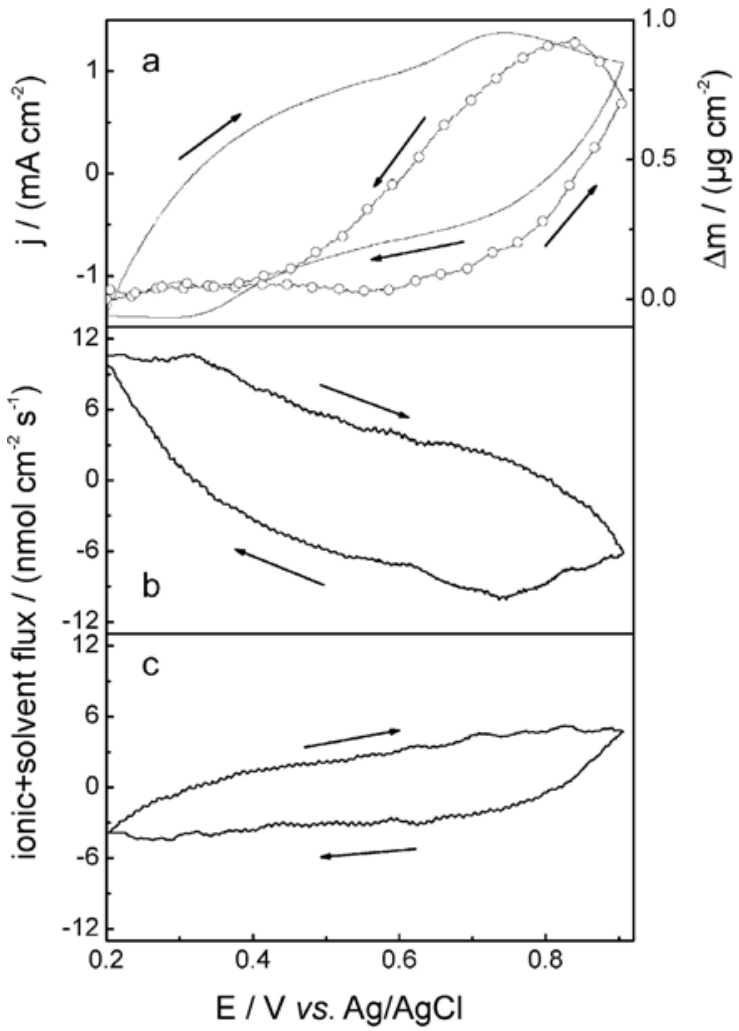

Figure 8. (a) Potentiodynamic $j / E$ (full line) and $\Delta m / E$ (open circle) profiles for FeTPPZFeCN/PPy films; (b) cation and (c) anion molar fluxes as a function of potential. Data calculated from Figure 8a. Electrolytic solution: $0.1 \mathrm{~mol} \mathrm{~L}^{-1} \mathrm{KClO}_{4}$. Film thickness $=500 \mathrm{~nm} . \mathrm{v}=50 \mathrm{mV} \mathrm{s}^{-1}$.

participation will depend mainly on cation mobility through the polymer matrix. Therefore, the mass change during the whole oxidation process in Figure 6 can be considered a balance between cation expulsion and anion incorporation. When the potential sweep is reversed, the direction of the flux is inverted.

In order to study the influence of anions, the same experiments in $\mathrm{KClO}_{4}$ were carried out, as shown in Figure 8. In this case, the shape of the voltammograms is very different in $\mathrm{KClO}_{4}$ solution than with the chloride salts used before. It shows an oxidation current peak at $+0.74 \mathrm{~V}$ and the reduction one at $0.32 \mathrm{~V}$ and a global increase of mass during oxidation followed by the corresponding decrease of mass during reduction. Some differences between the molar fluxes of ions during the cyclic voltammograms for the $\mathrm{KCl}$ (Figure 7) and $\mathrm{KClO}_{4}$ (Figure 8) electrolytic solutions can be inferred showing a diminution of the anions + solvent flux for perchlorate solutions. This fact is a consequence of the greater molar mass of perchlorate, indicating that the magnitude of the anions's flux is also dependent on the identity of the anion of the supporting electrolyte, similar to that observed previously for the film without PPy.

By comparing these results with those obtained in previous publications ${ }^{19}$ about charge compensation 
dynamics in PPy films, it can be inferred that they are very similar indicating that the inorganic complex acts as the immobilized counter ion of the PPy, and all the dynamics and nature of the charge compensation process is controlled in this case by the ability of the PPy matrix to accommodate ions of different charge and size.

\section{Conclusions}

FeTPPZFeCN and FeTPPZFeCN/PPy composite film were electrochemically obtained and characterized by FTIR. For both cases, in $\mathrm{KCl}$ electrolyte, EQCM data indicate that the participation of $\mathrm{K}^{+}$in the charge compensation process was almost negligible and most of the charge was compensated by the insertion of chloride ions. Moreover, it was found that for supramolecular film, anion transport is greater in a $\mathrm{K}^{+}$containing solution than in $\mathrm{Li}^{+}$solution. Therefore, the ionic compensation dynamics depends on the chemical nature of the cation, specifically, on the mass/charge relationship. This behavior is different when compared to PB films, where the contribution of anions to charge neutralization process is negligible. In the case of the hybrid film FeTPPZFeCN/PPy, the magnitude of the anions's flux is also dependent on the identity of the anion of the supporting electrolyte.

\section{Acknowledgments}

Financial support from Brazilian agencies FAPESP (Grant No. 03/10015-3) and Conselho Nacional de Desenvolvimento Científico e Tecnológico (CNPq-MCT) (Grant No. 555592/2006-5) are gratefully acknowledged. This work was also supported by international exchange collaboration CAPES (Brazil) and SPU (Argentine) (Grant No. 025/05).

\section{References}

1. Lehn, J. -M.; Chem. Eur. J. 2000, 6, 2097; Balzani, V.; Credi, A.; Raymo, F. M.; Stoddart, J. F.; Angew. Chem. Int. Ed. 2000, 39, 3348; Desiraju, G. R.; Nature 2001, 412, 397; Mulder, A.; Huskens, J.; Reinhoudt, D. N.; Org. Biomol. Chem. 2004, 2, 3409; Araki, K.; Toma, H. E.; Quim. Nova 2002, 25, 962; Descalzo, A. B.; Martínez-Máñez, R.; Sancenón, F.; Hoffmann, K.; Rurack, K.; Angew. Chem. Int. Ed. 2006, 45, 5924.

2. Bernhard, S.; Goldsmith, J. I.; Takada, K.; Abruña, H. D.; Inorg. Chem. 2003, 42, 4389; Díaz, D. J.; Storrier, G. D.; Bernhard, S.; Takada, K.; Abruma, H. D.; Langmuir, 1999, 15 , 7351; Maskus, M.; Abruña, H. D.; Langmuir 1996, 12, 4455; Nogueira, A. F.; Toma, S. H.; Vidotti, M.; Formiga, A. L. B.; Córdoba de Torresi, S. I.; Toma, H. E.; New J. Chem. 2005, 29 ,
320; Kosbar, L.; Srinivasan, C.; Afzali, A.; Graham, T.; Copel, M.; Krusin-Elbaum, L.; Langmuir 2006, 22, 7631; Alves, W. A.; Cerchiaro, G.; Paduan-Filho, A.; Tomazela, D. M.; Eberlin, M. N.; Ferreira, A. M. D. C.; Inorg. Chim. Acta 2005, 358, 3581.

3. Storrier, G. D., Takada, K.; Abruña, H. D.; Langmuir 1999, 15, 872; Chanda, N.; Laye, R. H.; Chakraborty, S.; Paul, R. L.; Jeffery, J. C.; Ward, M. D.; Lahiri, G. K.; J. Chem. Soc., Dalton Trans. 2002, 3496; Chanda, N.; Sarkar, B.; Fiedler, J.; Kaim, W.; Lahiri, G. K.; J. Chem. Soc., Dalton Trans. 2003, 3550; Koley, M.; Sarkar, B.; Ghumaan, S.; Bulak, E.; Fiedler, J.; Kaim, W.; Lahiri, G. K.; Inorg. Chem. 2007, 46, 3736.

4. Padgett, C. W.; Pennington, W.T.; Hanks, T. W.; Crystal Growth Design 2005, 5, 737.

5. Saragnapani, S.; U.S. Patent 447,114 1997.

6. Herrick, S. E.; Laurent, G. J. U.K.; Patent Appl. GB 2,376,886 2002.

7. Lakowicz, J. R.; Castellano, F.; Murtaza, Z.; Int. Pat. Appl. WO 9,936,779 1999

8. Brewer, K.; Swavey, S.; U. S. Patent Appl. U.S. 2,003,280,767 2003.

9. Sauers, A. L.; Ho, D. M.; Bernhard, S.; J. Org. Chem. 2004, 69, 8910.

10. Collin, J. P.; Laine, P.; Sauvage, J. P.; Sour, A.; J. Chem. Soc., Chem. Commun. 1993, 434; Vogler, L. M.; Brewer, K. J.; Inorg. Chem. 1996, 35, 818; Lee, J. D.; Vrana, L. M.; Bullock, E. R.; Brewer, K. J.; Inorg. Chem. 1998, 37, 3575; Hartshorn, C. M.; Daire, N.; Tondreau, V.; Loeb, B.; Meyer, T. J.; White, P. S.; Inorg. Chem. 1999, 38, 3200; Metcalfe, C.; Spey, S.; Adams, H.; Thomas, J. A.; J. Chem.Soc., Dalton Trans. 2002, 4732.

11. Constable, E. C.; Chem. Commun. 1997, 1073; Ishow, E.; Gourdon, A.; Launay, J. -P.; Lecante, P.; Verelst, M.; Chiorboli, C.; Scandola, F.; Bignozzi, C. -A.; Inorg. Chem. 1998, 37, 3603.

12. Alves, W. A.; Fiorito, P. A.; Cordoba de Torresi, S. I.; Torresi, R. M.; Biosens. Bioelectron. 2006, 22, 298.

13. Hammache, H.; Makhloufi, L.; Saidani, B.; Synth. Met. 2001, 123,515

14. Sauerbrey, G.; Z. Phys. 1959, 155, 206.

15. Gabrielli, C.; Keddam, M.; Torresi, R. M.; J. Electrochem. Soc. 1991, 138, 2657.

16. Varela, H.; Malta, M.; Torresi, R. M.; Quim. Nova 2000, 23, 664; Buttry, D. A.; Ward, M. D.; Chem. Rev. 1993, 92, 1355.

17. Itaya, K.; Ataka, T.; Toshima, S.; J. Am. Chem. Soc. 1982, 104, 4767.

18. Sant'Ana, A. C., Alves, W. A., Santos, R. H. A., Ferreira, A. M. D. C., Temperini, M. L. A.; Polyhedron 2003, 22, 1673; Cruz, A. G. B.; Wardell, J. L.; Rangel, M. V. D.; Simão, R. A.; Rocco, A. M.; Synth. Met. 2007, 157, 80; Sahoo, N. G.; Jung, Y. C.; So, H. H.; Cho, J. W.; Synth. Met. 2007, 157, 374.

19. Maia, G.; Torresi, R. M.; Ticianelli, E. A.; Nart, F. C.; J. Phys. Chem. 1996, 100, 15910; Varela, H.; Bruno, R. L.; Torresi, R. M.; Polymer 2003, 44, 5369. 
20. Zhang, Y.; Inorg. Chem. 1982, 21, 3886; Zhang, Y.; Inorg. Chem. 1982, 21, 3889.

21. Oh, I.; Lee, H.; Yang, H.; Kwak, J.; Electrochem. Commun. 2001, 3, 274; Lin, C. -L.; Ho, K. -C.; J. Electroanal. Chem. 2002, 524-525, 286; Kim, K.; Jureviciute, I.; Bruckenstein, S.; Electrochim. Acta 2001, 46, 4133; Lee, H.; Yang, H.; Kim, Y. T.; Kwak, J.; J. Electrochem. Soc. 2000, 147, 3801.

22. Itaya, K.; Uchida, I.; Neff, V. D.; Accounts Chem. Res. 1986. 19,162 .
23. Ricci, F.; Palleschi, G.; Biosen. Bioelectron. 2005, 21, 389.

24. Varela, H.; Torresi, R. M.; Buttry, D. A.; J. Braz. Chem. Soc. 2000, 11, 32.

25. Torresi, R. M.; Cordoba de Torresi, S. I., Matencio, T.; De Paoli, M. -A.; Synth. Met. 1995, 72, 283.

Received: October 2, 2007

Web Release Date: March 28, 2008

FAPESP helped in meeting the publication costs of this article. 